• 研究报告・

\title{
基于稳定同位素技术的塔里木河下游不同林龄 胡杨的水分利用来源
}

\author{
张 江 $^{1}$ 李桂芳 ${ }^{1}$ 贺亚玲 ${ }^{2}$ 穆雨迪 $^{3}$ 庄 丽 ${ }^{*}$ 刘红玲 $4^{*}$ \\ 1 (石河子大学生命科学学院新疆植物药资源利用教育部重点实验室, 新疆石河子 832003) \\ 2 (石河子大学医学院, 新疆石河子 832003) \\ 3 (华东师范大学生命科学学院, 上海 200241) \\ 4 (成都师范学院化学与生命科学学院, 成都 610101)
}

\begin{abstract}
摘要: 水分是制约很多陆地生态系统植物生长和繁殖的重要因素, 在干旱地区尤为明显。利用稳定同位素技术探 究塔里木河下游不同林龄胡杨(Populus euphratica)的水分来源情况，了解生态输水背景下荒漠河岸林的水分利用 循环与利用策略, 可为生态输水提供科学依据, 同时也可对同类地区的生态恢复提供借鉴。本研究通过测定塔里 木河下游胡杨茎干水和各潜在水源(土壤水、地下水)的稳定氢氧同位素值 $\left(\delta \mathrm{D} 、 \delta^{18} \mathrm{O}\right)$, 应用多源线性混合模型 (IsoSource)分析了各潜在水源对不同林龄胡杨的贡献比例, 并结合3种林龄胡杨不同土壤深度含水量的变化, 分析 了胡杨的主要吸水层位。结果表明: (1)不同林龄胡杨样地的不同深度区间上的土壤水 $\delta^{18} \mathrm{O}$ 值存在显著差异 $(P<0.05)$ : 胡杨幼龄木、成熟木、过熟木木质部 ${ }^{18} \mathrm{O}$ 分别为 $-7.83 \pm 0.07 \%$ 、 $-8.53 \pm 0.11 \%$ 、 $-9.36 \pm 0.21 \%$; 而 $\delta \mathrm{D}$ 值不存在显著差异 $(P>0.05)$ 。可据此来推断胡杨的主要吸水层位。(2)总体上, 三种林龄胡杨土壤水 $\delta^{18} O$ 值随土壤 深度增加而减小, 并趋于接近地下水的 $\delta^{18} \mathrm{O}$ 值。其中, 0-60 $\mathrm{cm}$ 土壤水受蒸发影响比较大, 其同位素组成经历了强 烈的蒸发分馏过程，土壤含水量极少，土壤水 $\delta^{18} \mathrm{O}$ 值偏正。(3)不同林龄胡杨所利用的水分来源不同: 胡杨幼龄木对 于地表 $80 \mathrm{~cm}$ 以下的土壤水以及地下水均有一定程度的利用, 对 80-140 cm、140-220 $\mathrm{cm}$ 和220-340 $\mathrm{cm}$ 的土壤水平 均利用比率依次为 $16.2 \% 、 21.4 \%$ 和 $24.6 \%$, 对地下水平均利用比率为 $24.5 \%$; 成熟木主要利用 $220-340 \mathrm{~cm}$ 的土壤水 及地下水, 平均利用比率分别为 $36.9 \%$ 和 $42.3 \%$; 过熟木主要利用 $140-340 \mathrm{~cm}$ 的土壤水及地下水, 平均利用比率分 别为 $32.8 \%$ 和 $49.3 \%$ 。
\end{abstract}

关键词：氢氧稳定同位素; 水分利用来源; 土壤水; 林龄; 胡杨; 地下水

\section{Water utilization sources of Populus euphratica trees of different ages in the lower reaches of Tarim River}

\author{
Jiang Zhang ${ }^{1}$, Guifang $\mathrm{Li}^{1}$, Yaling $\mathrm{He}^{2}$, Yudi Mu${ }^{3}$, Li Zhuang ${ }^{1 *}$, Hongling $\mathrm{Liu}^{4 *}$ \\ 1 Key Laboratory of Xinjiang Phytomedicine Resource Utilization of Ministry of Education, College of Life Sciences, \\ Shihezi University, Shihezi, Xinjiang 832003 \\ 2 Faculty of Medicine, Shihezi University, Shihezi, Xinjiang 832003 \\ 3 College of Life Sciences, East China Normal University, Shanghai 200241 \\ 4 College of Chemistry and Life Science, Chengdu Normal University, Chengdu 610101
}

\begin{abstract}
Water availability is one of the most important factors affecting the growth and reproduction of terrestrial plants, particularly in arid regions. Understanding the strategies of desert riparian plants to circulate and utilize water can reveal the scientific basis for ecological water conveyance engineering and contribute to planning ecological restoration of similar areas. In this study, we examined whether Populus euphratica trees of different ages in the lower reaches of Tarim River differed in their water sources by using the stable hydrogen and oxygen isotope technology. Specifically, for P. euphratica of different ages in the same habitat, we measured hydrogen and oxygen stable isotope ratios $\left(\delta \mathrm{D}\right.$ and $\left.\delta^{18} \mathrm{O}\right)$ values of xylem water and potential
\end{abstract}

收稿日期: 2017-12-31; 接受日期: 2018-05-03

基金项目: 国家自然科学基金(31560177)

* 通讯作者 Co-authors for correspondence. E-mails: zhuangliii@163.com; 157164088@qq.com 
water sources (soil moisture and ground water). Then, we used multi-isotope mass balance analysis (IsoSource) to calculate the possible contributions of potential water sources to the total water content in plants. We found significant differences of $\delta^{18} \mathrm{O}$ value for soil moisture at different soil depths. Also, the $\delta^{18} \mathrm{O}$ values of young wood $(-7.83 \pm 0.07 \%)$, mature wood $(-8.53 \pm 0.11 \%$ o) and over-mature wood $(-9.36 \pm$ $0.21 \%$ ), which were significantly different, while $\delta \mathrm{D}$ values did not differ statistically among the forest types. Furthermore, $\delta^{18} \mathrm{O}$ values of $P$. euphratica in three kinds of forest age became lower while the distance was deeper from soil surface and gradually approached to ground water on the whole. The shallow soil water in 0-60 cm was significantly affected by evaporation. The isotopic composition of soil water had experienced a strong evaporation and fractionation process. And soil water content was small, while $\delta^{18} \mathrm{O}$ values were large. Finally, our results showed that water utilization of $P$. euphratica of different ages came from different sources. The young wood of $P$. euphratica used an average of $16.2 \%$ of its water from $80-140 \mathrm{~cm}$ of the soil, $21.4 \%$ from $140-220 \mathrm{~cm}$, and $24.6 \%$ from $220-340 \mathrm{~cm}$ and the average utilization ratio of ground water was $24.5 \%$. In comparison, mature wood of $P$. euphratica mainly utilized the water from 220-340 cm of the soil and the ground water, with the utilization rate being $36.9 \%$ and $42.3 \%$, respectively. Over-mature wood had water utilization ratios of $32.8 \%$ from $140-340 \mathrm{~cm}$ of soil and $49.3 \%$ of ground water.

Key words: stable oxygen and hydrogen isotopes; water utilization sources; soil water; forest age; Populus euphratica; ground water

胡杨 (Populus euphratica) 为杨柳科杨属植物, 是该属中最原始、最古老的一种, 系上新世古地中 海残遗物种。1984年, 胡杨被列为《中国濒危保护 植物名录》的III级濒危保护植物种, 随后在1993年 联合国粮农组织(FAO)林木基因资源专家组例会上 被确定为全世界干旱和半干旱地区急需优先保护 的林木基因资源(王世绩, 1996)。胡杨是荒漠河岸林 植被中重要的建群种和表征种, 在塔里木河两岸分 布较为集中, 对于稳定流域的生态平衡、防风固沙、 调节绿洲气候和形成肥沃的森林土壤具有十分重 要的作用, 是塔里木河流域农牧业发展的天然屏障 (陈亚宁等, 2003; 徐海量等, 2003; 赵峰侠和尹林克, 2007)。由于胡杨林是在自然条件下形成的, 它的生 长发育与环境条件特别是土壤水分状况有着极为 密切的关系。而日趋频繁的人类活动导致整个流域 地表水资源重新分配, 使得干流下游水分补给不足, 胡杨林已逐步衰败和退化(季方等, 2001)。为了拯救 胡杨这一珍贵的基因资源, 国内外学者进行了多层 面研究(李卫红等, 2009; 马建新等, 2010; Zhuang et al, 2010; Price et al, 2012), 其中水分循环、水分来源 及水分利用效率等问题一直是众多学者关注的热 点(陈拓等, 2002; 司建华等, 2007; 陈亚鹏等, 2011; 周天河等, 2015)。

水是影响陆地干旱生态系统整体稳定性的主 要因素之一(陈亚宁等, 2003)。在恶劣环境的胁迫下, 植物需要努力改变自身的生长模式才能够适应并 生存下去。随着生境的变化有选择性的将不同水源
作为自己生存的保障, 就是植物适应环境的一种表 现(曾巧和马剑英, 2013)。所以, 研究植物水分来源 有助于了解植物在干旱胁迫下的选择性, 从而针对 性地进行植物保护。在同位素技术未普及之前，虽 然有不少方法可以使用, 但是真正实施起来有一定 的困难和局限性(Meinzer et al, 2001)。很多对于植 物根系的直接研究(包括挖掘等手段)是不可取的, 这些方式会对植物生境造成不必要的破坏，且耗时 耗力(张建锋和周金星, 2006)。尤其是在具有多个可 利用水分来源的地区，比如地下水位较浅或者附近 有径流的地区，通过常规方法来探索潜在水源对植 物的贡献就显得更加困难了(段德玉和欧阳华, 2007)。稳定同位素技术作为一种重要的研究手段, 近年来在生态学的诸多领域中得到广泛应用 (Burgess et al, 2000; 孙双峰等, 2005; 邓文平等, 2013)。已有研究证明, 除一些泌盐植物和旱生植物 外，植物根系吸收土壤水分的过程中，稳定氢氧同 位素一般不会发生分馏。水分在被植物根系吸收后 沿木质部向上运输直至到达植物叶片的过程是以 液流形式进行的, 这种运输方式发生在植物体内, 水分不存在汽化现象, 因而一般也不存在稳定氢氧 同位素的分馏现象(Ross \& Brien, 1991; Lin \& Sternberg, 1994; 石辉等, 2003)。因此, 只要各潜在 水源的稳定同位素组成具有显著性差异, 那么将植 物木质部水分与各潜在水源的同位素组成进行对 比分析即可确定植物对不同水源的选择性(余绍文 等, 2011; 祁亚淑等, 2015)。 
本研究以塔里木河下游的胡杨为研究对象, 基 于土壤-根系子系统(李嘉竹和刘贤赵, 2008), 利用 稳定同位素D、 ${ }^{18} \mathrm{O}$ 重点对塔里木河下游不同林龄胡 杨的水分来源进行测定, 并结合对不同林龄胡杨样 地土壤含水量的分析，计算不同潜在水源对幼龄 木、成熟木、过熟木等不同林龄胡杨的贡献比率，探 究国家生态输水背景下不同林龄胡杨的水分利用 状态及干旱区胡杨林的水分分配机制, 为制定塔里 木河下游人工生态用水配置方案和胡杨林的恢复 提供科学依据。

\section{材料与方法}

\section{1 研究区概况}

塔里木河下游地区主要指卡拉水文站以下至 台特玛湖, 是由西北向东南方向穿行于塔克拉玛干 沙漠和库鲁克沙漠之间狭长的冲积平原, 为中国最 干旱地区之一。年降水量仅17.4-42.0 mm (平均降水 量33.6 mm), 年蒸发量高达2,500-3,000 mm, 属于 典型的暖温带大陆性干旱气候。年均气温 $10.7^{\circ} \mathrm{C}$, 年积温 $4,167.7^{\circ} \mathrm{C}$, 太阳总辐射量为 $6,180 \mathrm{MJ} / \mathrm{m}^{2}$, 年 日照数约 $3,118.7 \mathrm{~h}$, 无霜期 220 天, 风沙危害严重。 研究样地处于大西海子水库与阿拉干之间的英苏 附近的胡杨林带。塔里木河下游河道按河流特征可 分为上下两段。大西海子至阿拉干段为双河道, 北 侧为其文阔尔河, 河长 $204.5 \mathrm{~km}$, 南侧为老塔河, 河长143.8 km。阿拉干至台特玛湖, 河长 $153.1 \mathrm{~km}$, 呈南北向狭长带状分布。从2000年开始, 国家启动 了塔里木河流域综合治理工程, 生态输水使得沿河 一定区域的地下水位明显抬升, 天然植被恢复较 好。英苏监测断面距离河道约750 m范围内地下水 平均埋深维持在2-6 m, 已达到植物生长繁殖所需 的比较合理的水平 (邓铭江等, 2017; 刘迁迁等, 2017)。下游生长有廊道式的天然植被, 主要乔木是 胡杨, 灌木有柽柳(Tamarix chinensis)、黑果枸杞 (Lycium ruthenicum)、铃铛刺(Halimodendron halodendron)等，草本有芦苇(Phragmites australis)、花花 柴(Karelinia caspica)、胀果甘草(Glycyrrhiza inflata)等。

\section{2 样品采集}

在样地内选择具有代表性的无人工干扰的样 点, 分别选取3棵生长健康、长势较好的胡杨幼龄 木、成熟木、过熟木进行木质部样品和土壤水样品
的取样。采样时间为2016年8月, 采样前后几天内无 降雨产生也无凝结水生成。胡杨林龄的判别标准参 考录叙德等(1980), 不同林龄胡杨特征见表1。

\subsection{1 土壤含水量和土壤同位素水}

不同林龄样地土壤剖面的取样深度均设为 $340 \mathrm{~cm}$, 按0-100 cm每 $20 \mathrm{~cm}$ 为一层, 100-340 cm每 $40 \mathrm{~cm}$ 一层, 进行人工土钻取样。用于测定土壤含水 量的土壤装入铝盒中，在实验地立即称鲜重，带回 实验室于 $105^{\circ} \mathrm{C}$ 烘箱中烘干至恒重，计算土壤含水 量。土壤同位素水样品迅速装入玻璃瓶中，盖好瓶 塞，用封口膜parafilm密封，放入冰盒带回实验室， 并置于 $-20^{\circ} \mathrm{C}$ 冰箱冷冻保存, 用于同位素的测定。

\subsection{2 植物木质部}

为了避免光照的影响, 在同一天上午 8:0010:00采集向阳面相同高度的胡杨枝条上位置相同 的木质部, 为消除气孔蒸腾作用造成的同位素富集, 选择生长超过两年的茎, 取直径约 0.3-0.5 mm、长 约3-5 cm的枝条段, 将枝条段的外皮和韧皮部去掉, 保留木质部。保存方式与土壤同位素水样品相同。

\subsection{3 地下水}

地下水取自胡杨林附近的监测水井。塔里木河 流域管理局在样地附近设有地下水监测井, 井深可 达8-17 m, 用以监测河岸1,050 m范围内的地下水 位埋深变化, 其井水可作为地下水测定其 $\delta \mathrm{D} 、 \delta^{18} \mathrm{O}$ 值(刘迁迁等, 2017)。

\section{3 室内分析}

\subsection{1 样品水分提取}

土壤水和植物木质部水分采用低温真空蒸馏 法(王涛等, 2009; 刘文茹, 2013 ${ }^{\circledR}$ )提取。该技术虽然提 取系统较为复杂, 花费时间较长, 但是提取的土壤

\section{表1 不同林龄胡杨的植株特征}

Table 1 Tree characters of different ages of Populus euphratica

\begin{tabular}{|c|c|c|c|c|c|}
\hline & $\begin{array}{l}\text { 样本数 } \\
\text { No. of } \\
\text { samples }\end{array}$ & $\begin{array}{l}\text { 树高 } \\
\text { Height } \\
\text { (m) }\end{array}$ & $\begin{array}{l}\text { 胸径 Diame- } \\
\text { ter at breast } \\
\text { height }(\mathrm{cm})\end{array}$ & $\begin{array}{l}\text { - 冠幅 } \\
\text { Crown } \\
(\mathrm{m} \times \mathrm{m})\end{array}$ & $\begin{array}{l}\text { 林龄 } \\
\text { Forest } \\
\text { age (yr) }\end{array}$ \\
\hline $\begin{array}{l}\text { 幼龄木 } \\
\text { Young wood }\end{array}$ & 3 & $3-5$ & $8.13 \pm 0.47$ & $1.2 \times 1.5$ & $5-6$ \\
\hline $\begin{array}{l}\text { 成熟木 } \\
\text { Mature wood }\end{array}$ & 3 & $8-12$ & $56.63 \pm 5.05$ & $5.0 \times 6.5$ & $25-35$ \\
\hline $\begin{array}{l}\text { 过熟林 } \\
\text { Over-mature wood }\end{array}$ & 3 & $14-17$ & $104.93 \pm 5.48$ & $10.0 \times 11.0$ & $55-60$ \\
\hline
\end{tabular}

(1) 刘文茹 (2013) 提取方式和测定方法对氢氧稳定同位素的影响及其 在花生作物水源解析的应用. 硕士学位论文, 南京农业大学, 南京. 
水和植物水为纯水, 可避免其他物质对氢氧稳定同 位素分析的影响。相对于其他提取手段(共沸蒸馏、 离心分离等), 该技术提取误差较小, 结果准确, 被 广泛应用于土壤和植物水分提取。经过试验真空蒸 馏 $\delta \mathrm{D}$ 和 $\delta^{18} \mathrm{O}$ 的提取精度分别达到 $\pm 0.3 \%$ 和 $\pm 0.03 \%$ 。

\subsection{2 水分样品分析}

由清华大学稳定同位素实验室用MAT 253同位 素比率质谱仪(Isotope Ratio Mass Spectrometer)测 定土壤水、木质部水和地下水稳定氢氧重轻同位素 比率, 并与国际标准物(SMOW) 比对后计算出样品 的 $\delta \mathrm{D} 、 \delta^{18} \mathrm{O}$ 值。

$$
\begin{aligned}
& \delta \mathrm{D}(\%)=\left(\mathrm{R}_{\text {sample }} / \mathrm{R}_{\text {standard }}-1\right) \times 1000 \\
& \delta^{18} \mathrm{O}(\%)=\left(\mathrm{R}_{\text {sample }} / \mathrm{R}_{\text {standard }}-1\right) \times 1000
\end{aligned}
$$

其中, $\delta \mathrm{D} 、 \delta^{18} \mathrm{O}$ 分别为对应样品的稳定氢、氧同位

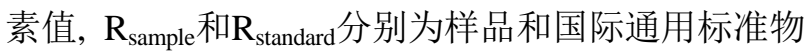
PDB (Pee Dee Belemnite, 一种海洋中的贝壳化石, 其 ${ }^{13} \mathrm{C}$ 含量为 $11.24 \%$ )中元素的重轻同位素丰度之比 (如 ${ }^{18} \mathrm{O} /{ }^{16} \mathrm{O}$ )。测定精度: $\delta^{18} \mathrm{O}: \pm<0.2 \%$, $\delta \mathrm{D}: \pm<1 \%$ 。

\section{4 水源的划分}

由于划分的土壤深度区间较多, 直接将每层土 壤水都作为一种水源来计算比较困难, 且不准确, 所以我们根据不同深度区间土壤水 $\delta^{18} \mathrm{O} 、 \delta \mathrm{D}$ 值是否 存在显著性差异进行合并计算。运用SPSS 17.0软件 的单因素方差分析进行多重比较(LSD) 可知, 幼龄 木的20-80 cm、80-220 cm、220-340 cm, 成熟木的 0-80 cm、100-220 cm、220-340 cm及过熟木的40$100 \mathrm{~cm} 、 140-340 \mathrm{~cm}$ 间的 $\delta^{18} \mathrm{O}$ 值不存在显著差异, 其他区间差异显著, 而 $\delta \mathrm{D}$ 值分子量很小, 且规律不 明确。三种林龄胡杨木质部水的 $\delta^{18} \mathrm{O}$ 值差异显著, $\delta \mathrm{D}$ 值则不存在显著性差异 $(P<0.05)$ 。据此推断胡杨 的主要吸水层位及计算各潜在水源贡献比率。

\section{5 水分来源的判断}

(1)直接对比: 将胡杨木质部水 $\delta^{18} \mathrm{O}$ 值与各潜 在水源进行对比分析, 若木质部水与某种潜在水 源 $\delta^{18} \mathrm{O}$ 值接近或相交, 此区域即为胡杨的主要吸水 层位。

(2) 由于本研究中胡杨的潜在水源较多, 所以 运用IsoSource模型定量分析胡杨对于各潜在水源 的利用比率。基于同位素质量守恒原理, 建立模型:

$$
\delta^{18} \mathrm{O}_{p}=\sum_{i=1}^{n} f_{i} \delta^{18} \mathrm{O}_{i}
$$

其中 $\delta^{18} \mathrm{O}_{p}$ 为胡杨木质部水的 $\delta^{18} \mathrm{O}$ 值; $\delta^{18} \mathrm{O}_{i}$ 为胡杨各 潜在水源的 $\delta^{18} \mathrm{O}$ 值; $\mathrm{f}_{i}$ 为胡杨对各水源的吸收比率。 模型运行时资源增量参数(source increment)设置为 $1 \%$, 质量平衡忍受差参数 (mass balance tolerance) 设置为 $0.01 \%$, 此时各潜在水源的贡献比率加权平 均值之和与胡杨木质部水 $\delta^{18} \mathrm{O}$ 值的差值小于 $0.01 \%$, 说明处于忍受范围内的组合是可行的(Benstead et al, 2006)。

\section{6 数据分析}

不同土层土壤水以及木质部水的 $\delta \mathrm{D}$ 和 $\delta^{18} \mathrm{O}$ 的 差异使用SPSS 17.0统计软件分析, 运用单因素方 差分析(95\%置信区间)进行多重比较(LSD)。用 Origin 8.0软件作图。

\section{结果}

\section{1 不同林龄胡杨样地土壤含水量}

不同林龄胡杨样地土壤含水量随土壤深度的 变化而变化(图1)。

幼龄木在0-80 $\mathrm{cm}$ 区间，土壤含水量极少，平 均仅为 $2.55 \%$, 这可能与浅层土壤受蒸发作用有关。 80-140 cm区间, 土壤水含量变化幅度较大, 出现 一个峰值, 这可能与幼龄木根系分布有关。在 140-220 cm范围内, 胡杨幼龄木土壤含水量增长幅 度较大, 并在180-220 cm之间再次出现峰值, 此时 含水量高达 $13.87 \%$, 这可能与地下水的补给有关。 而在220-340 cm, 土壤含水量又有所下降, 且变化 趋势比较平稳, 这可能是由于此深度幼龄木主要根 系尚无法触及, 受外界影响很小。

成熟木在0-40 $\mathrm{cm}$ 区间的土壤水含量极少，平 均仅为 $2.28 \%$, 与浅层土壤受蒸发作用的影响有关。

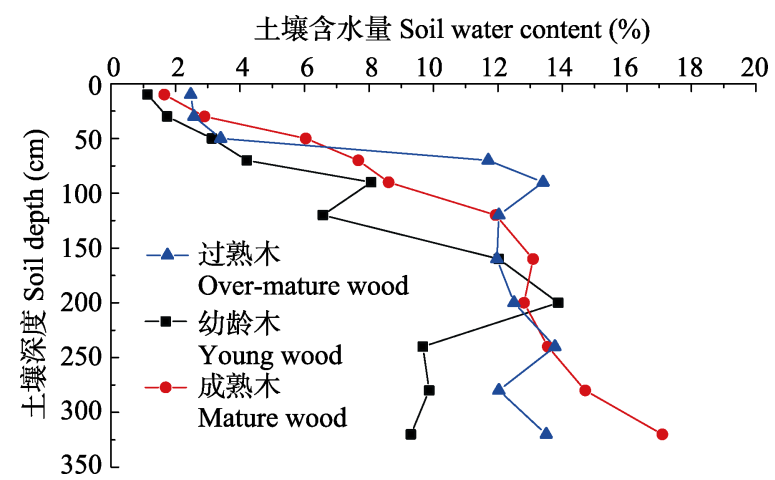

图1 不同林龄胡杨样地土壤剖面含水量

Fig.1 Soil water content in soil profile of different ages of Populus euphratica 
而自40 cm以下土壤水含量随着土壤深度的增加一 直呈增加趋势。从整个曲线上看, 选取的土壤深度 尚未达到其含水饱和层。

过熟木土壤含水量在0-60 cm区间变化范围为 2.47-3.4\%, 变化幅度很小, 含水量极低。在 $60-80 \mathrm{~cm}$ 区间，土壤含水量从 $3.4 \%$ 陡然增长至 $11.7 \%$, 变化 幅度较大。随后在80-340 cm区间变化幅度较小, 含 水量保持均衡, 在 $13 \%$ 左右波动。这可能与根系保 持土壤水分有关。

\section{2 不同林龄胡杨的主要吸水层位}

总体上, 胡杨土壤水 $\delta^{18} \mathrm{O}$ 值随土壤深度的增加 而减小, 并逐渐趋向于稳定(图2)。三种林龄胡杨土 壤剖面 $\delta^{18} \mathrm{O}$ 均在 $10 \mathrm{~cm}$ 左右出现最大值, 且数值非 常接近。幼龄木在 $0-80 \mathrm{~cm}$ 区间土壤水 $\delta^{18} \mathrm{O}$ 值较大, 在 80-220 cm区间 $\delta^{18} \mathrm{O}$ 值与木质部相交, 180-340 cm $\delta^{18} \mathrm{O}$ 波动幅度较小, 在 $-9.7 \%$ 。左右, 接近地下水的 $\delta^{18} \mathrm{O}$ 值; 成熟木土壤水 $\delta^{18} \mathrm{O}$ 在140-220 cm区间与木 质部相交, 220-340 cm波动幅度较小, 在-9.7\%。左
右波动，接近地下水的 $\delta^{18} \mathrm{O}$ 值; 过熟木木质部 $\delta^{18} \mathrm{O}$ 值与地下水非常接近，在140-340 cm区间，其土壤 水 $\delta^{18} \mathrm{O}$ 值呈现出稳定的趋势, 接近地下水与木质部 的 $\delta^{18} \mathrm{O}$ 值。

由此对比发现: 胡杨幼龄木的主要吸水层位为 80-220 cm; 成熟木主要吸水层位为 $140-220 \mathrm{~cm}$ 的 土壤水及地下水; 过熟木主要吸水层位包含 $140 \mathrm{~cm}$ 以下土壤水及地下水。

\section{3 不同林龄胡杨对各潜在水源的利用率}

我们将不同深度土壤水划分为几个可能水源, 幼龄木分为 $0-20 、 20-80 、 80-140 、 140-220$ 和 220-340 cm; 成熟木分为 $0-40 、 40-80 、 80-100$ 、 100-140、140-220和 $220-340 \mathrm{~cm}$; 过熟木分为 $0-20$ 、 20-40、40-100、100-140和140-340 cm。通过 IsoSource软件对不同深度土壤水及地下水对不同 林龄胡杨水分来源的贡献率进行了计算。结果表明 (图3): 胡杨幼龄木的水分主要来源于土壤 $80 \mathrm{~cm}$ 以 下，对于80-140、140-220和220-340 cm土壤水的平
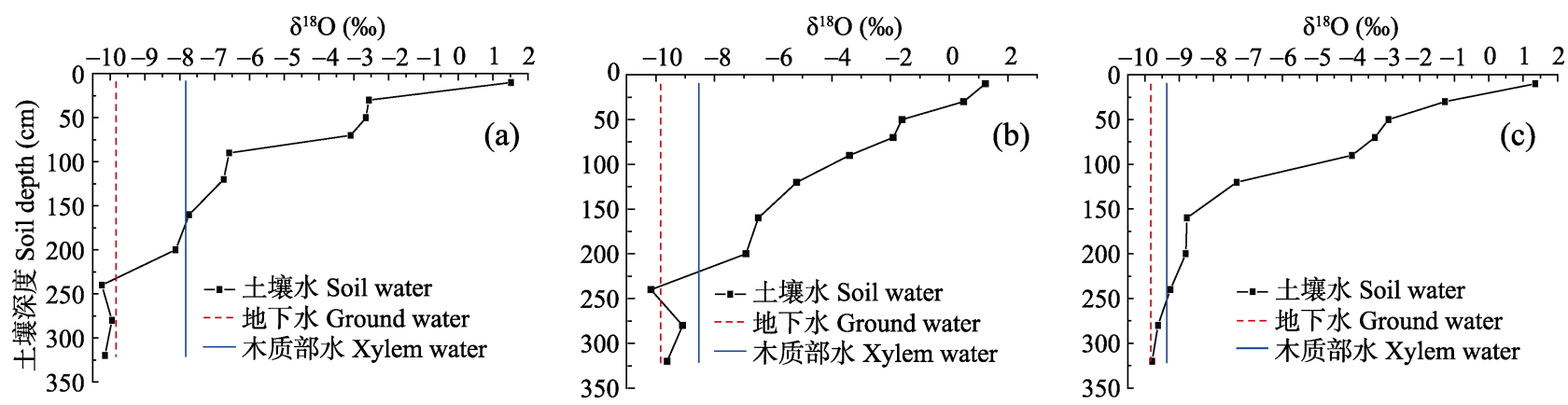

图2 不同林龄胡杨样地土壤水、地下水和木质部水 $\delta^{18} \mathrm{O}$ 值对比。(a)幼龄木; (b)成熟木; (c)过熟木。

Fig. 2 Comparison of $\delta^{18} \mathrm{O}$ values of soil water, xylem water and ground water of different ages of Populus euphratica. (a) Young wood; (b) Mature wood; (c) Over-mature wood.

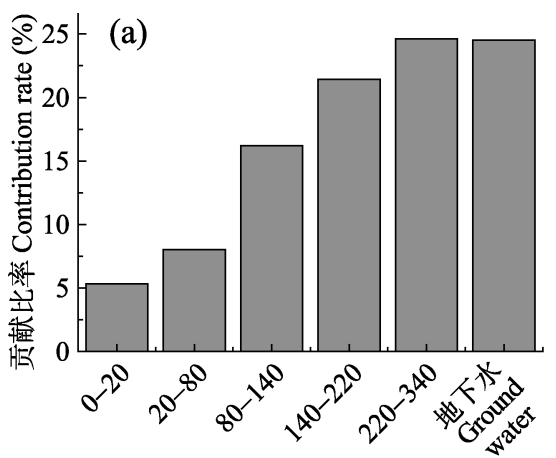

潜在水源 Potential water source $(\mathrm{cm})$

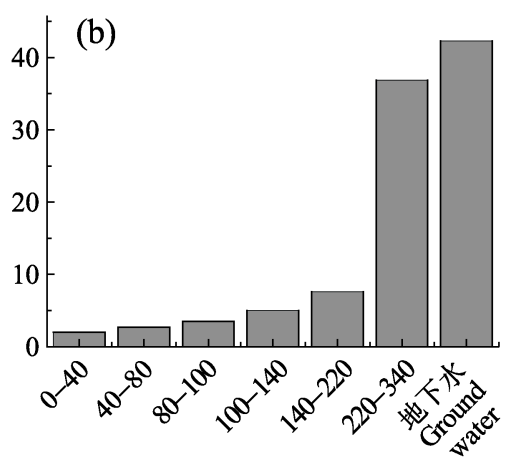

潜在水源 Potential water source $(\mathrm{cm})$

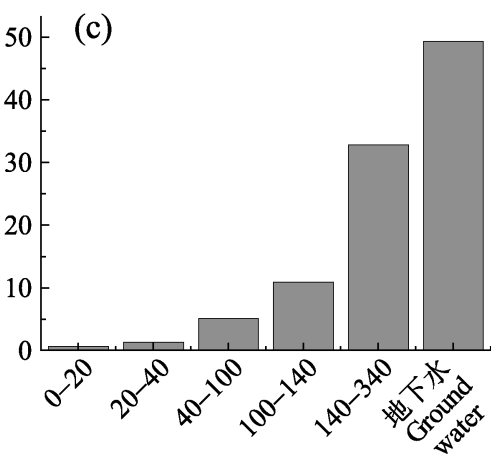

潜在水源 Potential water source $(\mathrm{cm})$

图3 各潜在水源对不同林龄胡杨(Populus euphratica)的贡献率。(a)幼龄木; (b)成熟木; (c)过熟木。

Fig. 3 The potential water sources and their contribution ratios to different ages of Populus euphratica. (a) Young wood; (b) Mature wood; (c) Over-mature wood. 
均利用比率依次为 $16.2 \%$ 、 $21.4 \%$ 和 $24.6 \%$, 对地下 水的平均利用比率为 $24.5 \%$; 成熟木主要利用 220-340 cm 土壤水和地下水, 平均利用比率分别为 $36.9 \%$ 和 $42.3 \%$; 过熟木主要利用 $140-340 \mathrm{~cm}$ 土壤水 和地下水, 平均利用比率分别为 $32.8 \%$ 和 $49.3 \%$ 。

\section{3 讨论}

不同林龄胡杨木质部水分 $\delta^{18} \mathrm{O}$ 值存在显著性差 异, $\delta \mathrm{D}$ 则差异不显著, 这表明根系在吸收土壤水分 期间发生了氢同位素分馏，与Ellsworth和Williams (2007)对耐盐旱生植物氢同位素分馏的研究结果不 谋而合。由于与耐盐和耐旱性相关的内胚层和外胚 层细胞壁发育程度较高, 植物更多地依赖于根系中 的共质体水分运输途径, 从而分离水分的氢同位素 (Ellsworth \& Williams, 2007)。除此之外, 土壤水 $\delta{ }^{18} \mathrm{O}$ 值和 $\delta \mathrm{D}$ 值均能表示土壤含水量, 但是两者的分 析结果并不一致, 不同林龄胡杨样地的不同深度土 壤水 $\delta^{18} \mathrm{O}$ 值存在区间性的显著差异，而 $\delta \mathrm{D}$ 值分子量 远小于 ${ }^{18} \mathrm{O}$, 且变化规律不明确, 这表明 $\mathrm{D}$ 的分馏更 容易受客观因素(水分在土壤中的水平迁移和垂直 运动)影响, 分馏效应较 ${ }^{18} \mathrm{O}$ 强。

在极端干旱的塔里木河下游, 土壤剖面表层受 蒸发作用而存在强烈的同位素分馏，而下界面则通 过水分提升作用接受地下水的补给，使得同位素不 再分馏, 趋向于稳定。不同深度土壤含水量的变化 趋势也印证了这一点。影响土壤水分中氢、氧稳定 性同位素分馏的有土壤水分入渗、蒸腾、蒸发等几 个方面, 塔里木河下游气候干燥, 降水稀少, 土壤 水分入渗不会影响同位素分馏。除某些排盐的盐生 植物外, 植物蒸腾作用对土壤水分的同位素是没有 影响的。因而，地表水分的蒸发是导致塔里木河下 游土壤水分中氢、氧稳定性同位素富集的主要原因。

胡杨幼龄木对地表 $80 \mathrm{~cm}$ 以下的土壤水源都有 一定的利用比率, 未形成主要的吸水层次, 而有些 学者对于幼龄木的研究结果是主要利用浅层土壤 水(刘树宝等, 2014), 这种差异可能与塔里木河下游 的降水、气温、土壤等因素的特异性有关。同时也 间接反映出生态输水工程造就的地下水位抬升的 良好效应使得幼龄木对水分来源有了更多更好的 选择。其次, 三种林龄胡杨的吸水层位存在着相当 大的重叠区域, 主要在于深层土壤水和地下水, 这 表明胡杨种内不同年龄阶段对于水分来源的利用
存在一种竞争关系。

三种林龄胡杨对地下水都有一定的利用比例, 尤其是成熟木和过熟木，对地下水的利用比率非常 高, 可以说其主要的水分来源就是地下水。由此可 见，在极端干旱的塔里木河下游，由于气候干燥、 降水稀少等外界不利因素的胁迫, 胡杨的生长繁殖 对地下水有很强的依赖性。因此实行塔河生态输水 工程、维持一定深度的地下水水位对维护塔里木河 下游河岸林植物的生存和生长极为重要。

不同类型的植物具有不同的水分利用来源，植 物在水分利用来源上存在着较大的时空变异, 尤其 在干旱半干旱地区(Nie et al, 2012)。而即便同种植 物，不同年龄阶段所利用的水分来源也有差异。胡 杨过熟木的吸水下限范围宽于成熟木，可能与其根 系分布更为广泛有关。可见随着胡杨林龄的增长, 其主要吸水层位趋向于更深、更稳定，应对极端干 旱环境的水分胁迫更为从容。除此之外，不同林龄 胡杨的水分利用策略还需结合对水分利用效率与 其他信息(蒸腾速率、光合速率、土壤和叶片水势等) 的测定分析, 才能获得一个较为完善的解释。

\section{参考文献}

Benstead JP, March JG, Fry B, Ewel KC, Pringle CM (2006) Testing IsoSource: Stable isotope analysis of a tropical fishery with diverse organic matter sources. Ecology, 87, 326-333.

Burgess SSO, Adams MA, Turner NC, Ward B (2000) Characterization of hydrogen isotope profiles in an agroforestry system: Implications for tracing water sources of trees. Agricultural Water Management, 45, 229-241.

Chen T, Feng HY, Xu SJ, Qiang WY, An LZ (2002) Stable carbon isotope composition of desert plant leaves and water-use efficiency. Journal of Desert Research, 22, 288-291. (in Chinese with English abstract) [陈拓, 冯虎元, 徐世建, 强维亚, 安黎哲 (2002) 荒漠植物叶片碳同位素组成及 其水分利用效率. 中国沙漠, 22, 288-291.]

Chen YN, Li WH, Xu HL, Liu JZ, Zhang HF, Cheng YP (2003) The influence of groundwater on vegetation in the lower reaches of Tarim River, China. Acta Geographica Sinica, 58, 542-549. (in Chinese with English abstract) [陈 亚宁, 李卫红, 徐海量, 刘加珍, 张宏峰, 程亚鹏 (2003) 塔里木河下游地下水位对植被的影响. 地理学报, 58, 542-549.]

Chen YP, Chen YN, Xu CC, Li WH, Fu AH (2011) Effects of groundwater depth on the gas exchange and chlorophyll fluorescence of Populus euphratica in the lower reaches of Tarim River. Acta Ecologica Sinica, 31, 344-353. (in Chi- 
nese with English abstract) [陈亚鹏, 陈亚宁, 徐长春, 李 卫红, 付爱红 (2011) 塔里木河下游地下水埋深对胡杨 气体交换和叶绿素荧光的影响. 生态学报, 31, 344-353.]

Deng MJ, Yang PN, Zhou HY, Xu HL (2017) Water conversion and strategy of ecological water conveyance in the lower reaches of the Tarim River. Arid Zone Research, 34, 717-726. (in Chinese with English abstract) [邓铭江, 杨鹏 年, 周海鹰, 徐海量 (2017) 塔里木河下游水量转化特征 及其生态输水策略. 干旱区研究, 34, 717-726.]

Deng WP, Yu XX, Liu YJ, Jia GD, Li YJ, Bai YJ (2013) Comparison of the methods using stable hydrogen and oxygen isotope to distinguish the water source of Quercus variabilis in dry season. Journal of Basic Science and Engineering, 21, 412-422. (in Chinese with English abstract) [邓文 平, 余新晓, 刘玉洁, 贾国栋, 李亚军, 白艳婧 (2013) 利用稳定氢氧同位素定量区分栓皮柇旱季水分来源的方 法比较. 应用基础与工程科学学报, 21, 412-422.]

Duan DY, Ouyang H (2007) Application of stable hydrogen and oxygen isotope in analyzing plant water use sources. Ecology and Environment, 16, 655-660. (in Chinese with English abstract) [段德玉, 欧阳华 (2007) 稳定氢氧同位 素在定量区分植物水分利用来源中的应用. 生态环境, 16, 655-660.]

Ellsworth PZ, Williams DG (2007) Hydrogen isotope fractionation during water uptake by woody xerophytes. Plant \& Soil, 291, 93-107.

Ji F, Ma YJ, Fan ZL (2001) Soil water regime in Populus euphratica forest on the Tarim River Alluvial Plain. Acta Phytoecologica Sinica, 25, 17-22. (in Chinese with English abstract) [季方, 马英杰, 禁自立 (2001) 塔里木河冲积平 原胡杨林的土壤水分状况研究. 植物生态学报, 25, 17-22.]

Li JZ, Liu XZ (2008) Advances of stable hydrogen and oxygen isotope applied in SPAC water cycle. Journal of Desert Research, 28, 787-794. (in Chinese with English abstract) [李 嘉竹, 刘贤赵 (2008) 氢氧稳定同位素在SPAC水分循环 中的应用研究进展. 中国沙漠, 28, 787-794.]

Li WH, Zhuang L, Gong WC, Zhao WQ, Tian ZP (2009) Ultramicroscopic structure of Populus euphratica leaves related to environmental heterogeneity in the lower reaches of Tarim River. Journal of Desert Research, 29, 680-687. (in Chinese with English abstract) [李卫红, 庄丽, 公维昌, 赵 文勤, 田中平 (2009) 塔里木河下游胡杨叶片变化与环 境异质性. 中国沙漠, 29, 680-687.]

Lin G, Sternberg LDS (1994) Utilization of surface water by red mangrove (Rhizophora mangle L.): An isotopic study. Bulletin of Marine Science, 54, 94-102.

Liu QQ, Gulimire H, Su LT, Zhang Y (2017) Response process of groundwater table to ecological water conveyance in the lower reaches of Tarim River riparian zone. Arid Land Geography, 40, 979-986. (in Chinese with English abstract) [刘迁迁, 古力米热 - 哈那提, 苏里坦, 张音 (2017) 塔里 木河下游河岸带地下水埋深对生态输水的响应过程. 干
旱区地理, 40, 979-986.]

Liu SB, Chen YN, Li WH, Chen YP, Ren ZG (2014) Application of $\mathrm{D}$ and ${ }^{18} \mathrm{O}$ stable isotopes in analyzing the water sources of different ages of Populus euphratica in the lower reaches of the Hei River. Arid Land Geography, 37, 988-995. (in Chinese with English abstract) [刘树宝, 陈亚 宁, 李卫红, 陈亚鹏, 任志国 (2014) 黑河下游不同林龄 胡杨水分来源的D、 ${ }^{18} \mathrm{O}$ 同位素示踪. 干旱区地理, 37, 988-995.]

Lu XD, An JW, Ren BJ (1980) Investigation report on aerial of Populus euphratica forest in Tarim basin. Forestry of Xinjiang, (6), 3-11, 47-49. (in Chinese) [录叙德, 安佳文, 任 伯建 (1980) 塔里木盆地胡杨林航视调查报告. 新疆林 业, (6), 3-11, 47-49.]

Ma JX, Chen YN, Li WH, Huang X, Zhu CG, Ma XD (2010) Response of sap flow in Populus euphratica to changes in groundwater depth in the middle and lower reaches of the Tarim River of northwestern China. Chinese Journal of Plant Ecology, 34, 915-923. (in Chinese with English abstract) [马建新, 陈亚宁, 李卫红, 黄湘, 朱成刚, 马晓东 (2010) 胡杨液流对地下水埋深变化的响应. 植物生态学 报, 34, 915-923.]

Meinzer FC, Clearwater MJ, Goldstein G (2001) Water transport in trees: Current perspectives, new insights and some controversies. Environmental and Experimental Botany, 45, 239-262.

Nie Y, Chen HS, Wang KL, Yang J (2012) Water source utilization by woody plants growing on dolomite outcrops and nearby soils during dry seasons in karst region of Southwest China. Journal of Hydrology, 420, 264-274.

Price RM, Skrzypek G, Grierson PF, Swart PK, Fourqurean JM (2012) The use of stable isotopes of oxygen and hydrogen to identify water sources in two hypersaline estuaries with different hydrologic regimes. Marine and Freshwater Research, 63, 952-966.

Qi YS, Zhu L, Xu X (2015) A review of applications of stable isotopes of hydrogen and oxygen for researches of soil water absorption of plants. Journal of Agricultural Sciences, (4), 51-57. (in Chinese with English abstract) [祁亚淑, 朱林, 许兴 (2015) 氢氧稳定同位素在植物水分提升机理研究 上的应用. 农业科学研究, (4), 51-57.]

Ross M, Brien JO (1991) Water relations of coastal plant communities near the ocean/freshwater boundary. Oecologia, 88, 305-310.

Shi H, Liu SR, Zhao XG (2003) Application of stable hydrogen and oxygen isotope in water circulation. Journal of Soil and Water Conservation, 17, 163-166. (in Chinese with English abstract) [石辉, 刘世荣, 赵晓广 (2003) 稳定性氢氧同位 素在水分循环中的应用. 水土保持学报, 17, 163-166.]

Si JH, Feng Q, Li JL, Zhao J (2007) Spatial distribution pattern of Populus euphratica fine roots in desert riparian forest. Chinese Journal of Ecology, 26, 1-4. (in Chinese with English abstract) [司建华, 冯起, 李建林, 赵健 (2007) 荒漠 
河岸林胡杨吸水根系空间分布特征. 生态学杂志, 26, 1-4.]

Sun SF, Huang JH, Lin GH, Zhao W, Han XG (2005) Application of stable isotope technique in the study of plant water use. Acta Ecologica Sinica, 25, 2362-2371. (in Chinese with English abstract) [孙双峰, 黄建辉, 林光辉, 赵威, 韩兴国 (2005) 稳定同位素在植物水分利用研究中的应用. 生态 学报, 25, 2362-2371.]

Wang SJ (1996) The status, conservation and recovery of global resources of Populus euphratica. World Forestry Research, (6), 37-44. (in Chinese with English abstract) [王世 绩 (1996) 全球胡杨林的现状及保护和恢复对策. 世界 林业研究, (6), 37-44.]

Wang T, Bao WM, Chen X, Shi Z, Hu HY, Qu SM (2009) Soil water extraction using vacuum distillation technology. Journal of Hohai University (Natural Sciences), 37, 660-664. (in Chinese with English abstract) [王涛, 包卫民, 陈翔, 施征, 胡海英, 睢思敏 (2009) 真空蒸馏技术提取 土壤水实验研究. 河海大学学报(自然科学版), 37, 660664.]

Xu HL, Chen YN, Yang G (2003) Effect of translating water on vegetation at the lower reaches of Tarim River. Environmental Science, 24(4), 18-22. (in Chinese with English abstract) [徐海量, 陈亚宁, 杨戈 (2003) 塔里木河下游生 态输水对植被和地下水位的影响. 环境科学, 24(4), 18-22.]

Yu SW, Zhang X, Duan LJ, Long X (2011) Application of stable hydrogen and oxygen isotope to the study of plant water use sources. Safety and Environmental Engineering, 18, 1-6. (in Chinese with English abstract) [余绍文, 张溪, 段丽军, 龙翔 (2011) 氢氧稳定同位素在植物水分来源 研究中的应用. 安全与环境工程, 18, 1-6.]
Zeng Q, Ma JY (2013) Plant water sources of different habitats and its environmental indication in Heihe River basin. Journal of Glaciology and Geocryology, 35, 148-155. (in Chinese with English abstract) [曾巧，马剑英 (2013) 黑河流 域不同生境植物水分来源及环境指示意义. 冰川冻土, 35, 148-155.]

Zhang JF, Zhou JX (2006) Research methods and mechanism of senescence of tree root: A review. Ecology and Environment, 15, 405-410. (in Chinese with English abstract) [张建 锋, 周金星 (2006) 林木根系衰老研究方法与机制. 生态 环境, 15, 405-410.]

Zhao FX, Yin LK (2007) Spatial distribution pattern and interspecific association of Populus euphratica and Tamarix ramosissima seedling populations along desert inland river. Chinese Journal of Ecology, 26, 972-977. (in Chinese with English abstract) [赵峰侠, 尹林克 (2007) 荒漠内陆河岸 胡杨和多枝柽柳幼苗种群空间分布格局及种间关联性. 生态学杂志, 26, 972-977.]

Zhou TH, Zhao CY, Yu YX, Wu GL, Wang LJ (2015) Study on the water source of Populus euphratica seedling and Tamarix ramosissima seedling based on stable hydrogen and oxygen isotope technology. Journal of Soil and Water Conservation, 29, 241-246. (in Chinese with English abstract) [周天河, 赵成义, 俞永祥, 吴桂林, 王丽娟 (2015) 基于 稳定氢氧同位素的胡杨与柽柳幼苗水分来源研究. 水土 保持学报, 29, 241-246.]

Zhuang L, She DY, Hu YF, Chen YN (2010) Historical evolution, ecological management and response of Tarim River Basin. Science in China Series D: Earth Sciences, 55, 4097-4103.

(责任编委: 邓建明 责任编辑: 黄祥忠) 